\title{
Proinflammatory response induced by Newcastle disease virus in tumor and normal cells
}

\section{Teridah Ernala Ginting Jeremiah Suryatenggara Salomo Christian George Mathew}

Division of Immunology, Mochtar Riady Institute for Nanotechnology and Medical Science Group, University of Pelita Harapan, Tangerang, Indonesia
This article was published in the following Dove Press journal:

Oncolytic Virotherapy

3 March 2017

Number of times this article has been viewed

Purpose: To investigate the specific role of immune responses induced by lentogenic Newcastle disease virus (NDV) for its antitumor effect.

Materials and methods: NDV LaSota strain was used to infect the following human cells: non-small cell lung carcinoma (A549), glioblastoma (U87MG and T98G), mammary gland adenocarcinoma (MCF7 and MDA-MB-453), hepatocellular carcinoma (Huh7), transformed embryonic kidney cells (HEK293), primary monocytes, lung fibroblast (HF19), skin fibroblast (NB1RGB) and rat astroglia (RCR-1) at 0.001 multiplicity of infection. NDV-induced cytotoxicity and expression of proinflammatory cytokines were analyzed using 3-(4,5-dimethylthiazol2-Y1)-2,5-diphenyltetrazolium bromide assay and multiplex enzyme-linked immunosorbent assay, respectively.

Results: Tumor cells (A549, U87MG, T98G, Huh7, MDA-MB-453, and MCF7) showed viability of $<44 \%$, while normal cell lines HEK293, NB1RGB, and RCR-1 showed 84\%, 73\%, and $69 \%$ viability at 72 hours postinfection, respectively. Proinflammatory cytokine profiling showed that NDV mainly induced the secretion of interferon (IFN)- $\alpha$, IFN- $\beta$, and IFN- $\lambda$ in tumor cells and only IFN- $\lambda$ in normal cells. In addition, NDV infection induced the production of interleukin (IL)-6 in most cells.

Conclusion: Our findings suggest a new perspective regarding the role of IFN- $\lambda$ and IL- 6 in the mechanism of tumor selectivity and oncolysis of NDV.

Keywords: Newcastle disease virus, oncolytic virus, interferons, cytokines

\section{Introduction}

Every year, mortality caused by cancer is increasing globally. This calls for novel therapeutic strategies. ${ }^{1}$ Use of oncolytic viruses represents a class of promising antitumor therapeutic options, primarily through the direct lysing of cancer cells and secondarily through the potential antitumor response induced by inflammation. ${ }^{2-6}$

Newcastle disease virus (NDV) is a negative-strand RNA virus from the family Paramyxoviridae. This virus has been reported to be an effective oncolytic agent in vitro and in vivo against many types of solid tumors such as hepatocellular carcinoma, pancreatic adenocarcinoma, melanoma, pleural mesothelioma, colorectal carcinoma, renal carcinoma, glioblastoma and many others, ${ }^{5,7-13}$ as well as in clinical studies in patients with glioblastoma multiforme, colorectal carcinoma, non-small cell lung carcinoma, renal carcinoma, breast adenocarcinoma, mesothelioma and pancreatic adenocarcinoma. ${ }^{14-18}$ NDV causes a disease that predominantly affects poultry, although infection in humans has been reported to cause conjunctivitis ${ }^{19,20}$ and/or mild flu-like symptoms. ${ }^{13-17,21}$ Based on their virulence on birds, NDV strains can be divided into
Mochtar Riady Institute for

Nanotechnology and Medical Science

Group, University of Pelita Harapan, Jalan

Boulevard Jenderal Sudirman 1688, Lippo

Karawaci, Tangerang, Banten I58II,

Indonesia

Tel +62 2154210123

Fax +622154210110

Email tginting@mrinstitute.org 
three groups: lentogenic (low virulence), mesogenic (medium virulence) and velogenic (high virulence). According to the properties of the viral fusion protein, NDV can be divided into lytic and nonlytic strains, both of which have antitumor potential. Lytic strains are able to produce infectious progeny, while nonlytic strains mainly stimulate immune responses that result in antitumor activity., $9,2,22$

Cells respond to viral infection by the production of antiviral cytokines, mainly interferon (IFN), which is reported to have antiproliferative effects against tumors. There are three types of IFNs, ie, type I IFNs (IFN- $\alpha$ and IFN- $\beta$ ), type II IFN (IFN- $\gamma$ ) and type III IFNs (IFN- $\lambda 1$, IFN- $\lambda 2$ and IFN- $\lambda 3$ ). Type I IFNs and type III IFNs are believed to stimulate similar IFN stimulating genes (ISGs) that have antiviral effects. The main function of type II IFN is in adaptive immune responses, although it may share some antiviral properties of type I and III IFNs. ${ }^{23-27} \mathrm{NDV}$ is postulated to be a potent type I IFN inducer, but due to defective IFN signaling in tumor cells NDV replicates better in tumor cells. This has been the basis of tumor selective replication of NDV. ${ }^{11,18,28-31}$ The evidence for type I IFN production in vitro and in vivo after NDV infection has been obtained by measuring the level of IFN- $\alpha / \beta$ and the induction of ISGs. Moreover, the presence of IFN protein has been reported in cell lines after being infected with nonengineered or engineered NDV. ${ }^{8,11,28}$ The difference in proinflammatory cytokine production between normal and tumor cells and the role in oncolysis upon NDV infection are not well understood.

The primary objectives of this study were to optimize the protocol for the use of lentogenic NDV LaSota strain as a safe antitumor agent and to investigate NDV susceptibil- ity of tumors. In this study, we were able to demonstrate the oncolytic activity of lentogenic NDV strain at low multiplicity of infection (MOI) in tumor cells compared to normal (nonmalignant) cells. This indicates for a mechanism involving soluble mediators that induce cell death. Furthermore, we found a difference in cytokine expression in tumor and normal cells, which may contribute to the basis of tumor selectivity of NDV.

\section{Materials and methods Cell culture}

Human tumor cell lines A549 (non-small cell lung carcinoma), U87MG (glioblastoma multiforme), T98G (glioblastoma multiforme), MDA-MB-453 (breast adenocarcinoma), MCF7 (breast adenocarcinoma) and Huh7 (hepatocellular carcinoma), and normal (nonmalignant) mammalian cells HEK293 (transformed embryonic kidney), H19 (lung fibroblast), NB1RGB (skin fibroblast) and RCR-1 (transformed astroglia) were purchased from RIKEN BioResource Center - Cell Bank (Tsukuba, Japan) or American Type Culture Collection (ATCC, Rockville, MD, USA) and cultured according to the protocol of the provider. All cells and culture conditions are listed in Table 1.

Fresh whole blood used to generate monocyte culture in this study was obtained from a healthy volunteer. Written informed consent was obtained and the ethical approval was granted from the Mochtar Riady Institute for Nanotechnology Ethics Committee. Peripheral blood mononuclear cells (PBMCs) were collected using Ficoll-paque (GE Healthcare Bio-Science, Uppsala, Sweden) according to the manufacturer's protocol. Then, PBMCs were allowed to adhere in a cell

Table I Conditions of normal and tumor cells

\begin{tabular}{|c|c|c|c|c|c|}
\hline Cell name & Code & Tissue & Species & $\begin{array}{l}\text { Growth medium } \\
\text { (+10\% FBS) }\end{array}$ & Culture condition \\
\hline \multicolumn{6}{|l|}{ Tumor } \\
\hline A549 & RCB0098 & Non-small cell lung carcinoma & Human & FI2-K & Adherent, $37^{\circ} \mathrm{C}, 5 \% \mathrm{CO}_{2}$ \\
\hline U87MG & НTBI4 & Glioblastoma multiforme & Human & High glucose DMEM & Adherent, $37^{\circ} \mathrm{C}, 5 \% \mathrm{CO}_{2}$ \\
\hline T98G & $\mathrm{RCBI} 954$ & Glioblastoma multiforme & Human & RPMI-I640 & Adherent, $37^{\circ} \mathrm{C}, 5 \% \mathrm{CO}_{2}$ \\
\hline Huh7 & $\mathrm{RCB} 1942$ & Hepatocellular carcinoma & Human & High glucose DMEM & Adherent, $37^{\circ} \mathrm{C}, 5 \% \mathrm{CO}_{2}$ \\
\hline MDA-MB-453 & $\mathrm{RCBI} / 92$ & Mammary gland adenocarcinoma & Human & Leibovitz-I5 & Adherent, $37^{\circ} \mathrm{C}$, no $\mathrm{CO}_{2}$ \\
\hline MCF7 & RCBI904 & Mammary gland adenocarcinoma & Human & $\begin{array}{l}\text { MEM + } 0.1 \text { mM NEAA } \\
+1 \mathrm{mM} \text { sodium pyruvate }\end{array}$ & Adherent, $37^{\circ} \mathrm{C}, 5 \% \mathrm{CO}_{2}$ \\
\hline \multicolumn{6}{|c|}{ Normal (nonmalignant) } \\
\hline HEK 293 & $\mathrm{RCBI} 637$ & Human embryonic kidney & Human & High glucose DMEM & Semi-adherent, $37^{\circ} \mathrm{C}, 5 \% \mathrm{CO}_{2}$ \\
\hline Monocytes & & Adherent mononuclear cells (primary) & Human & RPMI-I640 & Adherent, $37^{\circ} \mathrm{C}, 5 \% \mathrm{CO}_{2}$ \\
\hline NBIRGB & RCB0222 & Normal skin fibroblast & Human & $\operatorname{MEM} \alpha$ & Adherent, $37^{\circ} \mathrm{C}, 5 \% \mathrm{CO}_{2}$ \\
\hline HFI9 & $\mathrm{RCB} 0210$ & Normal lung fibroblast & Human & $\operatorname{MEM} \alpha$ & Adherent, $37^{\circ} \mathrm{C}, 5 \% \mathrm{CO}_{2}$ \\
\hline RCR-I & RCB0075 & Astroglia & Rat & DMEM & Semi-adherent, $37^{\circ} \mathrm{C}, 5 \% \mathrm{CO}_{2}$ \\
\hline
\end{tabular}

Abbreviations: DMEM, Dulbecco's Minimal Essential Medium; FBS, fetal bovine serum; FI2-K, Kaighn's modification FI2 nutrient medium; MEM, minimal essential medium; NEAA, nonessential amino acids; RPMI-1640, Roswell Park Memorial Institute-1640. 
culture dish for 30 minutes at $37^{\circ} \mathrm{C}$ in $5 \% \mathrm{CO}_{2}$ atmosphere and subsequently washed to remove floating cells. Adherent mononuclear cells were detached with accutase (Biowest, Nuaillé, France) at room temperature, counted, grown in 96-well plates in Roswell Park Memorial Institute-1640 media (RPMI-1640) and treated on the next day. All media and supplements were obtained from Biowest, except for Kaighn's modification F12 nutrient medium (F12-K), Leibovitz's-15 and minimal essential medium alpha $(\mathrm{MEM} \alpha)$ media that were obtained from Gibco-Life Technologies (Carlsbad, CA, USA).

\section{Virus}

Lentogenic NDV LaSota strain was cultivated and obtained from PT IPB Shigeta Animal Pharmaceuticals, Bogor, Indonesia. Virus was grown in the allantoic cavity of NDVseronegative 10-day-old embryonated chicken eggs. Eggs were incubated at $37^{\circ} \mathrm{C}$ with $50-60 \%$ humidity for 5 days and subsequently incubated at $4{ }^{\circ} \mathrm{C}$ overnight. ${ }^{32}$ Allantoic fluid containing virus was collected and cleared from debris by centrifugation at $3000 \times g$. Infectious particles were confirmed by end point dilution assay. Virus was stored in aliquots at $-80^{\circ} \mathrm{C}$ before use.

\section{Virus titration}

Baby hamster kidney (BHK-21) cells (RIKEN) were grown in Dulbecco's Minimal Essential Medium (DMEM; Biowest) supplemented with 10\% fetal bovine serum (FBS). A 96-well plate of BHK-21 cells was prepared on the previous day to be confluent at the time of assay. Wells were washed with phosphate-buffered saline (PBS) three times. Cells were then overlaid with $25 \mu \mathrm{L}$ of ten-fold serially diluted virus for 60 minutes at $37^{\circ} \mathrm{C}$ in $5 \% \mathrm{CO}_{2}$, washed with PBS three times and then incubated in maintenance medium (similar to growth medium except that FBS was replaced with $0.3 \%$ bovine serum albumin (BSA) fraction V (Gibco) and 1\% 1-(tosylamido-2-phenyl) ethyl chloromethyl ketone (TPCK)treated trypsin (Affymetrix, Cleveland, OH, USA). The cells were incubated at $37^{\circ} \mathrm{C}$ in $5 \% \mathrm{CO}_{2}$ for 5 days, fixed with $10 \%$ formalin for 30 minutes and stained with crystal violet. Tissue culture infectious dose 50 value was calculated according to Reed and Muench. ${ }^{33}$

\section{Virus infection for determination of cytokine production}

To study the cytokine production of cells that were infected by NDV, we prepared $\sim 5 \times 10^{5}$ cells per well in triplicate in sixwell plates 12-18 hours before infection. Cells were washed with PBS three times and then incubated with $200 \mu \mathrm{L}$ of virus in PBS at $0.001 \mathrm{MOI}$, at $37^{\circ} \mathrm{C}$ in $5 \% \mathrm{CO}_{2}$ atmosphere for 60 minutes. Noninfected control wells were prepared by incubating cells with PBS (Gibco). At the end of the incubation, the cells were washed with PBS to remove unbound virus and overlaid with $2 \mathrm{~mL}$ of corresponding maintenance medium without TPCK trypsin. Culture supernatant that was collected at 48 hours after infection was used for further assay. ${ }^{31}$

\section{Cytotoxicity of NDV}

Triplicates of $5 \times 10^{4}$ cells per well in 96-well plates were prepared 12-18 hours before infection. Cells were washed three times and overlaid with $200 \mu \mathrm{L}$ of maintenance medium without TPCK-treated trypsin containing NDV at an MOI of 0.001 . Noninfected cells served as negative controls. Cytotoxicity assays were conducted as previously described $^{34}$ by adding $100 \mu \mathrm{g}$ 3-(4,5-dimethylthiazol-2-Y1)2,5-diphenyltetrazolium bromide (MTT; Sigma, St. Louis, $\mathrm{MO}$, USA) reagent followed by incubation at $37^{\circ} \mathrm{C}$ in $5 \%$ $\mathrm{CO}_{2}$ for 4 hours. Purple crystal formed was solubilized with dimethylsulfoxide (DMSO; Sigma), and absorbance was read at $540 \mathrm{~nm}$. Data are presented as percentage of viability, which is the ratio of treated to Noninfected cells.

\section{Multiplex proinflammatory cytokines: enzyme-linked immunosorbent assay (ELISA)}

Responses of normal and tumor cells to NDV infection at $0.001 \mathrm{MOI}$ were determined by measuring proinflammatory cytokine production in cell culture supernatants by using a Veriplex ${ }^{\circledR} 16$-plex human cytokine ELISA kit (PBL Assay Science, Piscataway, NJ, USA) according to the manufacturer's protocol. Then, $50 \mathrm{~mL}$ supernatants from infected or noninfected cells, which were collected at 48 hours, were ultraviolet (UV) inactivated for 30 minutes for biosafety reasons and then diluted 1:1 in sample buffer followed by incubation in wells of 96-well plates that contained antibodies against 16 different proinflammatory cytokines, including IFN- $\alpha$, IFN- $\beta$, IFN- $\gamma$, IFN- $\lambda 1 / 2 / 3$ and cytokines released upstream and downstream of IFN signaling. Plates were incubated for 2 hours at room temperature and washed, and $50 \mu \mathrm{L}$ of biotinylated detection antibody was added. Plates were incubated for 1 hour at room temperature and washed and $50 \mu \mathrm{L}$ of chemiluminescent substrate was added. Chemiluminescent output was visualized and imaged using a VersaDoc 4000 imaging system (Bio-Rad, Hercules, CA, USA). Images were analyzed with Q-View ${ }^{\circledR}$ software (Quansys Bioscience, Logan, UT, USA). Data were obtained from triplicate wells, and graphs were constructed from the average pixel intensity. 


\section{Statistical analysis}

Cytokine quantification data were mean values from triplicate wells. Significance of treated and Noninfected groups was analyzed by two-tailed unpaired Student's $t$-test and presented in $P$-values. Only a $P$-value of $<0.001 \quad(* * * P<0.001$, $* * * * P<0.0001)$ was discussed.

\section{Results and discussion Susceptibility of normal and tumor cell lines to NDV infection}

To examine whether lentogenic NDV is able to kill normal cells and tumor cells, we conducted cytotoxicity assays at low MOI (0.001) of NDV. Normal and tumor cells in this study (Table 1) were selected to represent a wide range of tissue types and to demonstrate different responses that can result from NDV infection. Cells in 96-well plates were cocultured with NDV and examined for cytotoxicity at 0,24 , 48 and 72 hours. Our study showed that normal cells such as HEK293, NB1RGB and RCR-1 were relatively resistant to NDV infection with viabilities of 84,73 and $69 \%$ at 72 hours postinfection (PI; Figure 1A). Tumor cells A549, U87MG, T98G, Huh7, MDA-MB-453 and MCF7 cell lines were susceptible to NDV infection. As expected, almost all cells were dying at 72 hours PI with viabilities of $<44 \%$ (Figure 1B). Notably, HF19, a normal human lung fibroblast cell line, was more susceptible to NDV compared to other normal cells used with a viability of $22 \%$ at 72 hours PI (Figure 1A) as has been reported by other investigators. ${ }^{35}$ This is possibly associated with the nature of paramyxoviruses that have tropism for

A

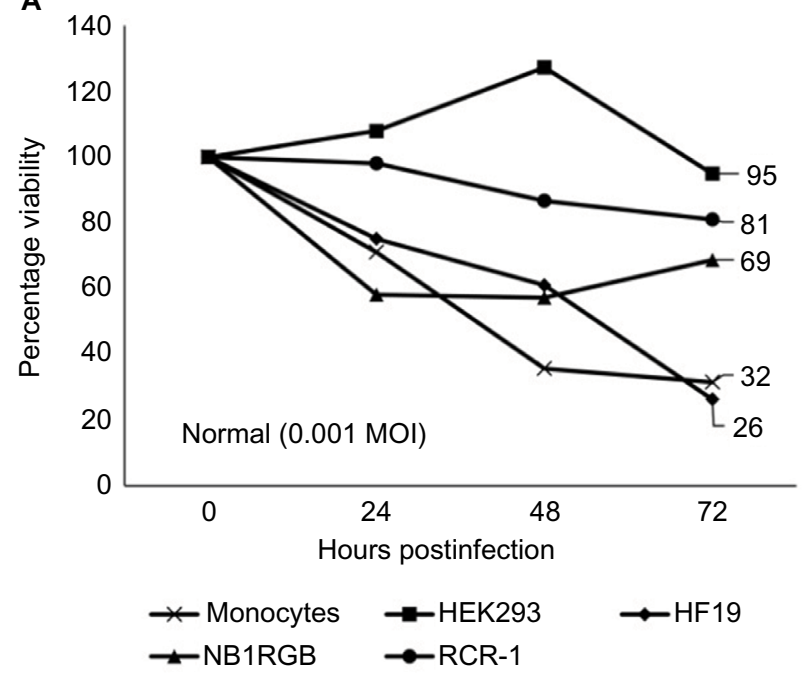

tissue in the respiratory tract. Human primary monocytes showed viability of $32 \%$ at 72 hours PI; however, the number was steady from 48 hours PI until the end of observation.

\section{A difference in IFN response in tumor cells when compared to normal cells after NDV infection}

To investigate whether the immune response induced by NDV is associated with the cytotoxicity, we infected normal and tumor cells with NDV at $0.001 \mathrm{MOI}$ and examined proinflammatory cytokines produced by cells after 48 hours of infection. This time point was chosen as most cells showed a remarkable reduction in viability (Figure 1), and this might be the consequence of cytokine expression.

We observed that NDV infection predominantly induced the production of both type I (IFN- $\alpha$ and IFN- $\beta$ ) and type III IFNs (IFN- $\lambda$ ) in tumor cells as was observed in A549, U87MG, T98G, MDA-MB-453 and MCF7; while NDV induced IFN- $\lambda$ production mainly in normal cells, ie, HEK293, HF19 and NB1RGB (Figure 2). Compared to IFN- $\alpha$ and $-\beta$, IFN- $\lambda$ production was very high in normal cells (Table S1) even when lower MOI was used. It is our contention that IFN- $\alpha$ and IFN- $\beta$ are not the major antiviral responses in normal cells. This suggests that NDV is a potent type III IFN inducer in normal and tumor cells. Higher induction of type III IFN was observed in all tumor cells except for Huh7. However, because some IFNs exhibited signals over the detection limit, it is unclear if each type of IFN was expressed differently in each tumor cell line used in this study.

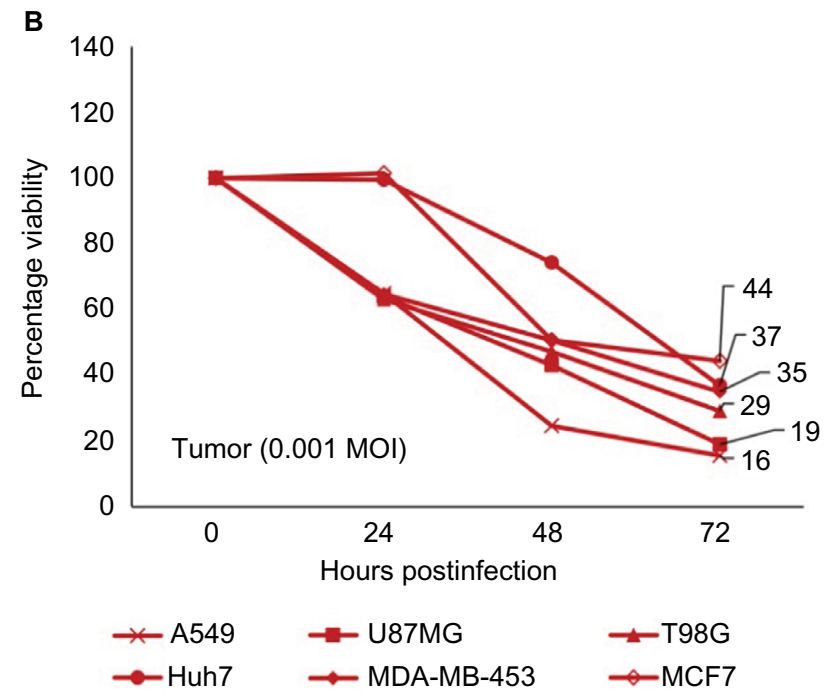

Figure I Cytotoxicity of NDV.

Notes: Cytotoxicity was evaluated every 24 hours by using MTT assay on normal cells (A) and tumor cells (B) at 0.00 I MOI. Percentage of viability was obtained from the ratio of treated cells with noninfected cells (not shown), where untreated cells were considered as $100 \%$ viable. Data were taken from triplicate wells.

Abbreviations: MOI, multiplicity of infection; MTT, 3-(4,5-dimethylthiazol-2-YI)-2,5-diphenyltetrazolium bromide; NDV, Newcastle disease virus. 


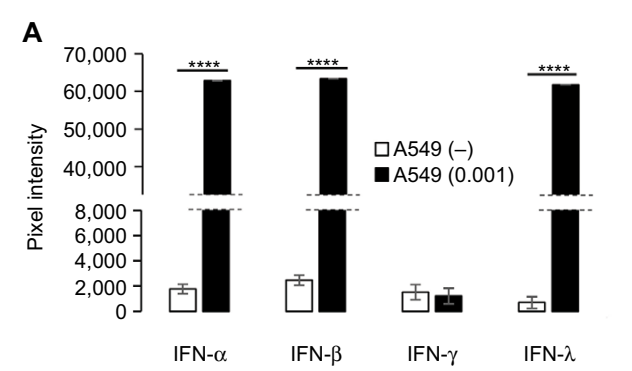

D

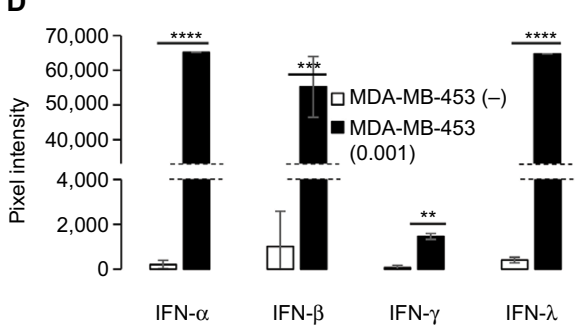

$\mathbf{G}$

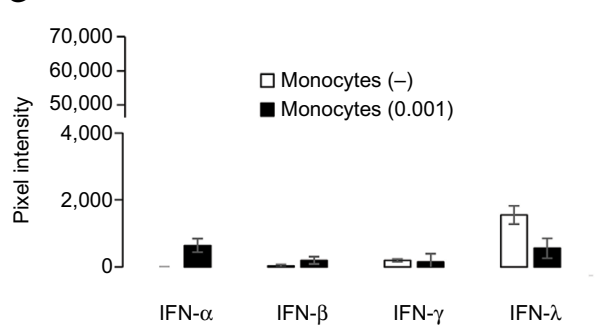

J

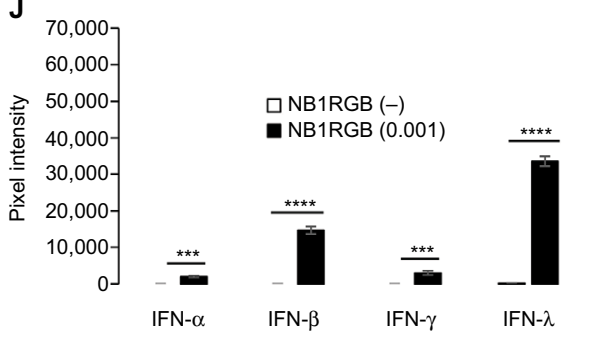

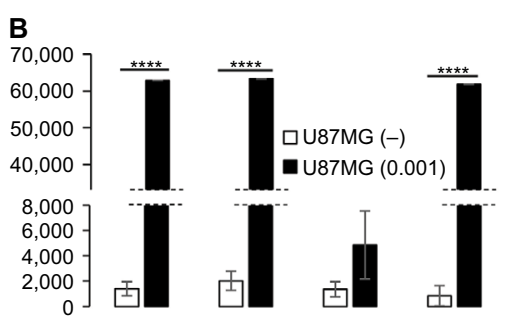

\section{$\mathrm{E}$}

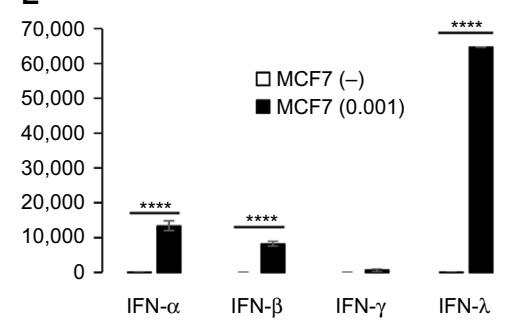

*

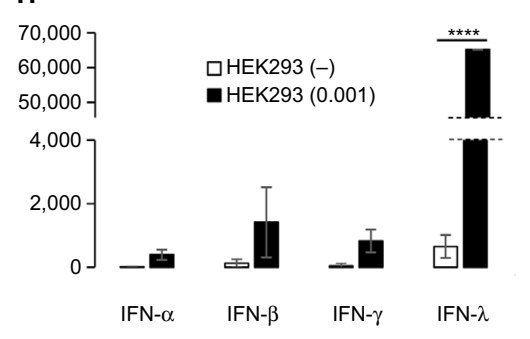

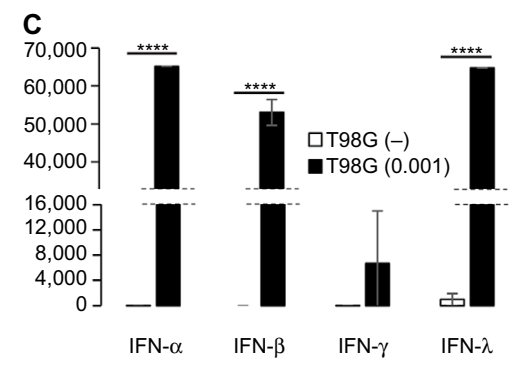

F

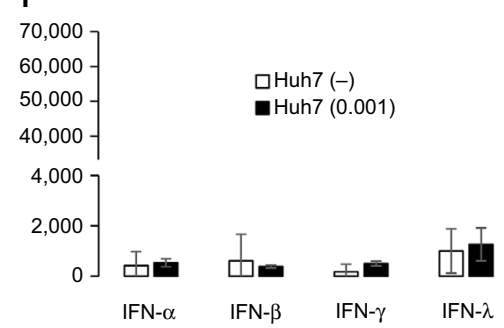

I

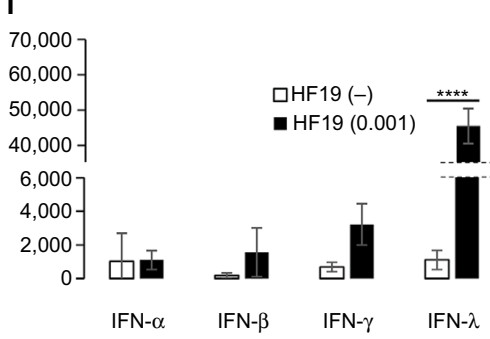

Figure 2 Type I, II and III IFNs production in tumor and normal cells.

Notes: (A) A549; (B) U87MG; (C) T98G; (D) MDA-MB0453; (E), MCF7; (F) Huh7; (G) monocytes (H) HEK293; (I) HFI 9; and (J) NBIRGB. IFNs in cell culture supernatant 48 hours after NDV infection at 0.001 MOI (black bars). Supernatant from noninfected cells $(-)$ are shown as white bars. Results are luminescence intensity that was taken from the average of triplicate wells and photographed by using VersaDoc 4000 imaging system. Pixel intensity was analyzed by Q-View software. Data represent means from triplicate wells. Standard deviation of mean is shown. $* * * P<0.001$, $* * * * P<0.000$ I.

Abbreviations: IFN, interferon; MOI, multiplicity of infection; NDV, Newcastle disease virus.

Hepatocellular carcinoma (Huh7) cells did not show any IFN expression above the lower limit of quantification, at least 48 hours after infection. Given the low percentage of viability observed in the cytotoxicity assay, Huh7 susceptibility to NDV was presumably not associated with direct IFN effects. Although type II IFN (IFN- $\gamma$ ) secretion was detected in U87MG and T98G, it was not at appreciable levels.

A previous study demonstrated the presence of type I IFNs in pancreatic adenocarcinoma cell lines upon NDV infection by measuring ISG expression. ${ }^{8}$ Another study also demonstrated that genetically engineered NDV induced IFN- $\alpha$ and IFN- $\beta$ in normal cells but only IFN- $\beta$ in most tumor cells; ${ }^{28}$ in addition, IFN- $\alpha$ was shown to be expressed in mouse bronchoalveolar lavage (BAL) and mouse/human monocytes. ${ }^{29}$ Yet, there have been no reports demonstrating that IFN- $\lambda$ is expressed higher than IFN- $\alpha / \beta$ in normal human cells after NDV infection.

\section{Characterization of other proinflammatory cytokines upon NDV infection}

Apart from the IFN response, we also evaluated the expression of a number of proinflammatory cytokines using a multiplex ELISA kit (Figure 3). In general, interleukin (IL)-8 was expressed in all cells in this study, and the level was increased after NDV infection; therefore, this cytokine is presumably expressed by cultured cells due to factors such as serum components contained in the media. We also observed that IL-6 was strongly expressed in most tumor cells, ie, A549, 
A

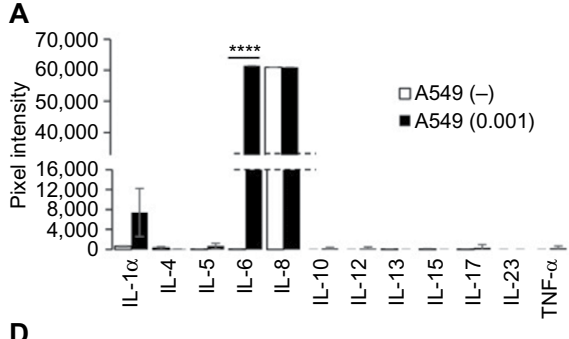

D
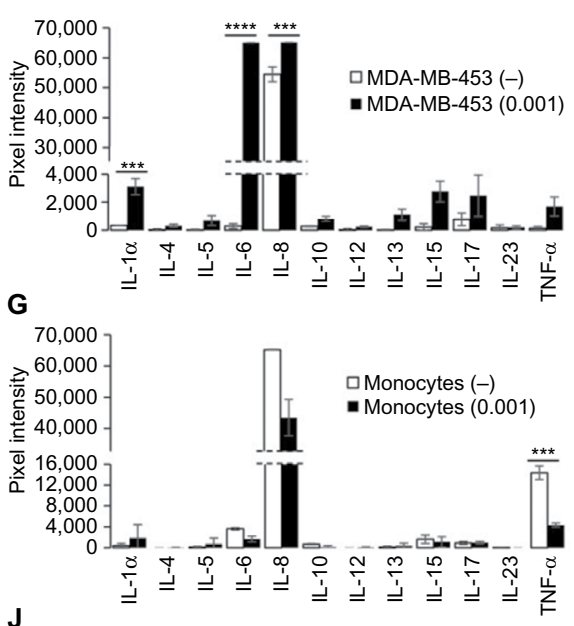

J

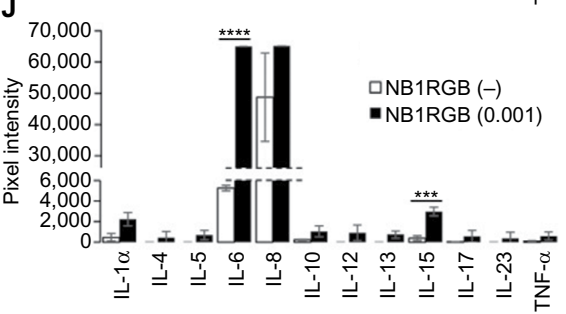

\section{B}

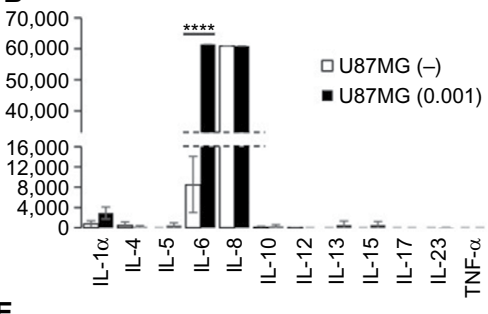

E

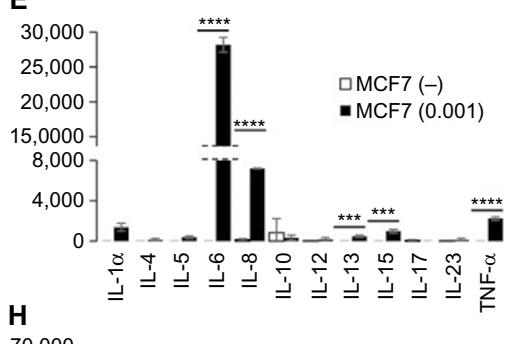

70,000

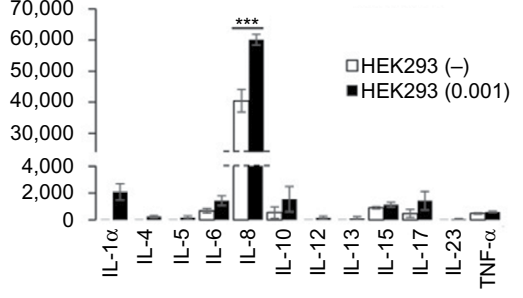

C

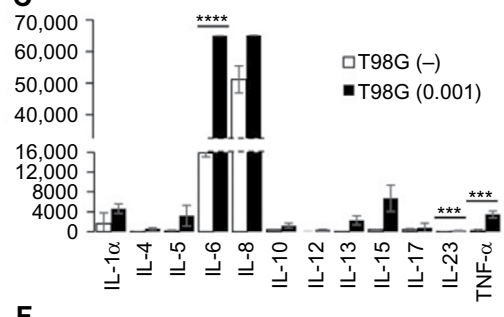

F

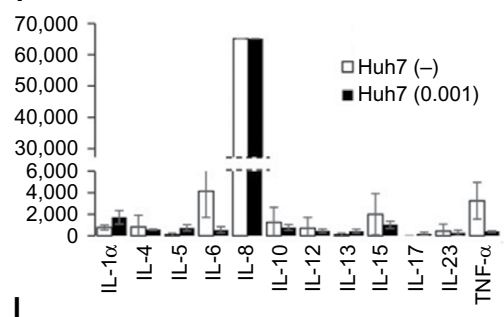

70,000

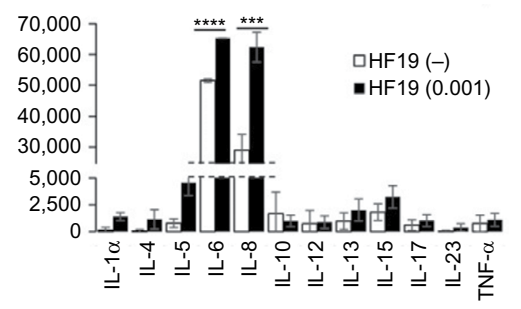

Figure 3 Production of proinflammatory cytokines other than IFNs.

Notes: (A) A549; (B) U87MG; (C) T98G; (D) MDA-MB0453; (E), MCF7; (F) Huh7; (G) monocytes (H) HEK293; (I) HFI9; and (J) NBIRGB. Other proinflammatory cytokines in cell culture supernatant 48 hours after NDV infection at $0.00 \mathrm{I}$ MOI (black bars). Supernatants from noninfected (-) cells are shown as white bars. Results are expressed as luminescence intensity that was recorded by using VersaDoc 4000 imaging system and analyzed by Q-View software. Data represent means from triplicate wells. Standard deviation of mean is shown. ***P<0.00I, ****P<0.000I.

Abbreviations: IL, interleukin; MOI, multiplicity of infection; NDV, Newcastle disease virus.

U87MG, T98G, MDA-MB-453 and MCF7, and some normal cells, ie, HF19 and NB1 RGB. IL-6 has been reported as being involved in the inflammatory response to viral infection in some cell lines, and its production is triggered through $\mathrm{NF} \kappa \mathrm{B}$ activation. ${ }^{36}$ However, whether IL-6 contributes to tumor specificity and oncolysis needs to be explored further. In addition, monocytes secreted TNF- $\alpha$ either naturally or after NDV infection. High cytotoxicity observed in monocyte culture after NDV infection is presumably because of apoptosis induction through the activation of TNF- $\alpha$ receptor-associated death domain (TRADD) that leads to apoptosis cascade. ${ }^{37}$ In tumor cell environment, the effects of TNF- $\alpha$ would be direct oncolysis, and a potential signal to produce IFNs in surrounding cells, thus indirectly killing tumor cells. ${ }^{29}$

\section{Conclusion}

The efficacy, safety and tumor selectivity have been the rationales of using NDV as antitumor agent. ${ }^{3,12,13,21,28,31}$ In this study, to demonstrate the cytotoxicity and tumor selectivity of NDV, we utilized a lentogenic LaSota strain, which has been long used as a vaccine strain worldwide, at low MOI. We examined IFN levels in cell culture supernatant after NDV infection and compared them to the cytotoxicity scores. Despite the hallmark of NDV as a potent type I IFN inducer, our results showed that NDV strongly induced type I IFNs only in tumor cells, while the induction was minor in normal cells. Indeed, we found that NDV is a very strong inducer of IFN- $\lambda$ in both normal and tumor cell types, even at a very low MOI.

The possible cause of the efficient killing rate of NDV in tumor cells (A549, U87MG, T98G, MDA-MB-453 and MCF7) when compared with normal cells (HEK293 and NB1RGB) could be because of the cumulative effects of type I IFNs (IFN- $\alpha$ and IFN- $\beta$ ) and type III IFN (IFN- $\lambda$ ), or the consequence of high expression of type I IFNs (IFN- $\alpha$ and IFN- $\beta$ ), which is peculiar to tumor cells. Both type I and 
III IFNs have antiproliferative effects, potentially stimulating the same genes, but they bind to different cell surface receptors. ${ }^{24-26,38}$ This finding introduces a new concept of NDV oncolysis: first, lentogenic nonlytic NDV is a very potent inducer of type I and III IFNs in human tumor cells, and second, the cumulative effect of IFNs induced by NDV results in better oncolysis rates in most tumor cells. Of all tumor cells used, hepatocellular carcinoma (Huh7) did not produce any IFNs although they showed cytotoxicity similar to other tumor cells. This suggests that the cytotoxicity of Huh7 in this study was driven by other mechanisms such as direct lysis due to virus replication.

Measurement of other cytokines showed that IL-6 was highly produced in most cell types after NDV infection, but because IL- 6 has both pro- and anti-inflammatory properties, ${ }^{39}$ further study is needed to conclude whether its expression leads to cytotoxicity or cell survival in NDV infection. IL-8, which is a chemotactic agent, functions to attract neutrophils during inflammation, also associated with malignancy and cell survival, and its production can be stimulated by many extracellular signals. ${ }^{40-43}$ High IL-8 production in all cells even in the Noninfected cells in this study was probably caused by the stimulation of other factors contained in the media. We tested each medium for the presence of proinflammatory cytokines but none were detected, thus confirming that there was no cytokine contamination.

Proinflammatory responses induced by NDV infection have been shown to have favorable effects on killing of tumor cells selectively. ${ }^{8,29,44}$ In this study, we conclude that lentogenic NDV LaSota strain has oncolysis ability at low MOI, presumably due to the effect of soluble mediator. We have shown that NDV-infected cells exhibit inflammatory response through the rise of IFNs and IL-6 in culture supernatant. Moreover, our study is the first to demonstrate different secretion of IFNs in normal and tumor cells and the presence of IFN- $\lambda$ in human cell lines upon NDV infection. However, exact mechanisms of cell death and tumor specificity of NDVinfected cells need to be determined further.

Given the important functions of IL- 6 in both proinflammatory and anti-inflammatory responses, and of type III IFNs to activate hundreds of IFN-stimulated genes that have effects such as antiviral, antiproliferation and inducing apoptosis, ${ }^{9,23-25,28,29,35}$ in this study we provide a strong rationale for further study of IL-6 and the balance of IFN- $\alpha$, IFN- $\beta$ and IFN- $\lambda$ in oncolysis and tumor specificity of NDV.

\section{Acknowledgments}

This study was supported by the Mochtar Riady Institute for Nanotechnology. The authors thank Dr Kamaluddin Zarkasie for kindly providing NDV LaSota strain and Dr Ben Peeters for critical discussion.

This study was approved by the Ethics Committee (EC) of the Mochtar Riady Institute for Nanotechnology (MRIN) (ethical approval number 011/MRIN-EC/01/2014).

\section{Disclosure}

The authors report no conflicts of interest in this work.

\section{References}

1. Forman D, Ferlay J. The global and regional burden of cancer. In: Stewart BW, Wild CP, editors. World Cancer Report 2014. Lyon: International Agency for Research on Cancer; 2014:26-71.

2. Auer R, Bell JC. Oncolytic viruses: smart therapeutics for smart cancers. Future Oncol. 2012;8(1):1-4.

3. Liu TC, Kirn D. Systemic efficacy with oncolytic virus therapeutics: clinical proof-of-concept and future directions. Cancer Res. 2007;67(2): 429-432.

4. Melcher A, Parato K, Rooney CM, Bell JC. Thunder and lightning: immunotherapy and oncolytic viruses collide. Mol Ther. 2011;19(6): 1008-1016.

5. Schirrmacher V, Fournier P. Newcastle disease virus: a promising vector for viral therapy, immune therapy and gene therapy of cancer. In: Walther W, Stein US, editors. Gene Therapy of Cancer SE - 30. Methods in Molecular Biology ${ }^{T M}$. Vol. 542. New York, NY: Humana Press; 2009:565-605. doi:10.1007/978-1-59745-561-9_30

6. Lichty BD, Breitbach CJ, Stojdl DF, Bell JC. Going viral with cancer immunotherapy. Nat Rev Cancer. 2014;14(8):559-567.

7. Altomonte J, Marozin S, Schmid RM, Ebert O. Engineered newcastle disease virus as an improved oncolytic agent against hepatocellular carcinoma. Mol Ther. 2010;18(2):275-284.

8. Buijs P, van Eijck C, Hofland L, Fouchier R, van den Hoogen B. Different responses of human pancreatic adenocarcinoma cell lines to oncolytic Newcastle disease virus infection. Cancer Gene Ther. 2014; 2178(10):24-30.

9. Reichard KW, Lorence RM, Cascino CJ, et al. Newcastle disease virus selectively kills human tumor cells. J Surg Res. 2016;52(5):448-453.

10. Silberhumer GR, Brader P, Wong J, et al. Genetically engineered oncolytic Newcastle disease virus effectively induces sustained remission of malignant pleural mesothelioma. Mol Cancer Ther. 2010; 9(10):2761-2769.

11. Zamarin D, Holmgaard RB, Subudhi SK, et al. Localized oncolytic virotherapy overcomes systemic tumor resistance to immune checkpoint blockade immunotherapy. Sci Transl Med. 2014;6(226):226ra32.

12. Schirrmacher V, Griesbach A, Ahlert T. Antitumor effects of newcastle disease virus in vivo: local versus systemic effects. Int J Oncol. 2001;18(5):945-952.

13. Khattar SK, Nayak B, Kim S-H, et al. Evaluation of the replication, pathogenicity, and immunogenicity of avian paramyxovirus (APMV) serotypes 2, 3, 4, 5, 7, and 9 in rhesus macaques. PLoS One. 2013; 8(10):e75456.

14. Batliwalla FM, Bateman BA, Serrano D, et al. A 15-year follow-up of AJCC stage III malignant melanoma patients treated postsurgically with Newcastle disease virus (NDV) oncolysate and determination of alterations in the CD8 T cell repertoire. Mol Med. 1998;4(12):783-794.

15. Forsyth P, Roldán G, George D, et al. A phase I trial of intratumoral administration of reovirus in patients with histologically confirmed recurrent malignant gliomas. Mol Ther. 2008;16(3):627-632.

16. Freeman A, Zakay-Rones Z, Gomori J, et al. Phase I/II trial of intravenous NDV-HUJ oncolytic virus in recurrent glioblastoma multiforme. Mol Ther. 2006;13(1):221-228.

17. Laurie SA, Bell JC, Atkins HL, et al. A phase 1 clinical study of intravenous administration of PV701, an oncolytic virus, using two-step desensitization. Clin Cancer Res. 2006;12(8):2555-2562. 
18. Pecora AL, Rizvy N, Cohen GI, et al. Phase I trial of intravenous administration of PV701, an oncolytic virus, in patients with advanced solid cancers. J Clin Oncol. 2002;20(9):2251-2266.

19. Nelson CB, Pomeroy BS, Schrall K, Park WE, Lindeman RJ. An outbreak of conjunctivitis due to Newcastle disease virus (NDV) occurring in poultry workers. Am J Public Health Nations Health. 1952;42(6):672-678.

20. Mustaffa-Babjee A, Ibrahim AL, Khim TS. A case of human infection with Newcastle disease virus. Southeast Asian JTrop Med Public Health. 1976;7(4):622-624.

21. Buijs PRA, van Amerongen G, van Nieuwkoop S, et al. Intravenously injected Newcastle disease virus in non-human primates is safe to use for oncolytic virotherapy. Cancer Gene Ther. 2014;21(11):463-471.

22. Sinkovics JG, Horvath JC. Newcastle disease virus (NDV): brief history of its oncolytic strains. J Clin Virol. 2016;16(1):1-15.

23. Ank N, Iversen MB, Bartholdy C, et al. An important role for type III interferon (IFN- $\lambda /$ IL-28) in TLR-induced antiviral activity. J Immunol. 2008;180(25):2474-2485

24. Ank N, West H, Bartholdy C, et al. Lambda interferon (IFN- $\lambda$ ), a type III IFN, is induced by viruses and IFNs and displays potent antiviral activity against select virus infections in vivo. J Virol. 2006;80(9):4501-4509.

25. Randall RE, Goodbourn S. Interferons and viruses: an interplay between induction, signalling, antiviral responses and virus countermeasures. $J$ Gen Virol. 2008;89(pt 1):1-47.

26. Zhou Z, Hamming OJ, Ank N, Paludan SR, Nielsen AL, Hartmann R. Type III interferon (IFN) induces a type I IFN-like response in a restricted subset of cells through signaling pathways involving both the Jak-STAT pathway and the mitogen-activated protein kinases. $J$ Virol. 2007;81(14):7749-7758.

27. Schroder K, Hertzog PJ, Ravasi T, Hume DA. Interferon- $\gamma$ : an overview of signals, mechanisms and functions. J Leukoc Biol. 2004;75(2):163-189.

28. Elankumaran S, Chavan V, Qiao D, et al. Type I interferon sensitive recombinant Newcastle disease virus for oncolytic virotherapy. JVirol. 2010;84(8):3835-3844.

29. Fournier P, Arnold A, Wilden H, Schirrmacher V. Newcastle disease virus induces pro-inflammatory conditions and type I interferon for counter-acting Treg activity. Int J Oncol. 2012;40(3):840-850.

30. Zamarin D, Martínez-Sobrido L, Kelly K, et al. Enhancement of oncolytic properties of recombinant Newcastle disease virus through antagonism of cellular innate immune responses. Mol Ther. 2009;17(4):697-706.
31. Fiola C, Peeters B, Fournier P, Arnold A, Bucur M, Schirrmacher V. Tumor selective replication of Newcastle disease virus: association with defects of tumor cells in antiviral defence. Int J Cancer. 2006;119(2):328-338.

32. OIE [World Organisation for Animal Health]. Newcastle disease. In: Afonso CL, Miller, PJ, Grund C, Koch G, Peeters B, Selleck PW, Srinivas GB, editors. Manual of Diagnostic Tests and Vaccines for Terrestrial Animals 2011. Paris: Office International des Epizooties; 2012:557.

33. Reed LJ, Muench H. A simple method of estimating fifty percent endpoints. Am J Epidemiol. 1938;27(3):493-497.

34. Kasugai $\mathrm{S}$, Hasegawa N, Ogura $\mathrm{H}$. A simple in vitro cytotoxicity test using the MTT (3-(4,5)-dimethylthiazol-2-yl)-2,5-diphenyl tetrazolium bromide) colorimetric assay: analysis of eugenol toxicity on dental pulp cells (RPC-C2A). Jpn J Pharmacol. 1990;52(1):95-100.

35. Zorn U, Dallmann I, Grosse J, Kirchner H, Poliwoda H, Atzpodien J. Induction of cytokines and cytotoxicity against tumor cells by Newcastle disease virus. Cancer Biother. 1994;9(3):225-235.

36. Mogensen TH, Paludan SR. Molecular pathways in virus-induced cytokine production. Microbiol Mol Biol Rev. 2001;65(1):131-135.

37. Rath PC, Aggarwal BB. TNF-induced signaling in apoptosis. $J$ Clin Immunol. 1999;19(6):350-364.

38. Goritzka M, Durant LR, Pereira C, Salek-Ardakani S, Openshaw PJM, Johansson C. Alpha/beta interferon receptor signaling amplifies early proinflammatory cytokine production in the lung during respiratory syncytial virus infection. J Virol. 2014;88(11):6128-6136.

39. Scheller J, Chalaris A, Schmidt-Arras D, Rose-John S. The pro- and anti-inflammatory properties of the cytokine interleukin-6. Biochim Biophys Acta. 2011;1813(5):878-888.

40. Waugh DJJ, Wilson C. The interleukin-8 pathway in cancer. Clin Cancer Res. 2008;14(21):6735-6741.

41. Hoffmann E, Dittrich-Breiholz O, Holtmann H, Kracht M. Multiple control of interleukin-8 gene expression. J Leukoc Biol. 2002;72(5): $847-855$.

42. He W, Luistro L, Carvajal D, et al. High tumor levels of IL6 and IL8 abrogate preclinical efficacy of the $\gamma$-secretase inhibitor, RO4929097. Mol Oncol. 2011;5(3):292-301.

43. Freund A, Chauveau C, Brouillet J-P, et al. IL-8 expression and its possible relationship with estrogen-receptor-negative status of breast cancer cells. Oncogene. 2003;22(2):256-265.

44. Biswas M, Kumar SR, Allen A, et al. Cell-type-specific innate immune response to oncolytic Newcastle disease virus. Viral Immunol. 2012; 25(4):268-276. 


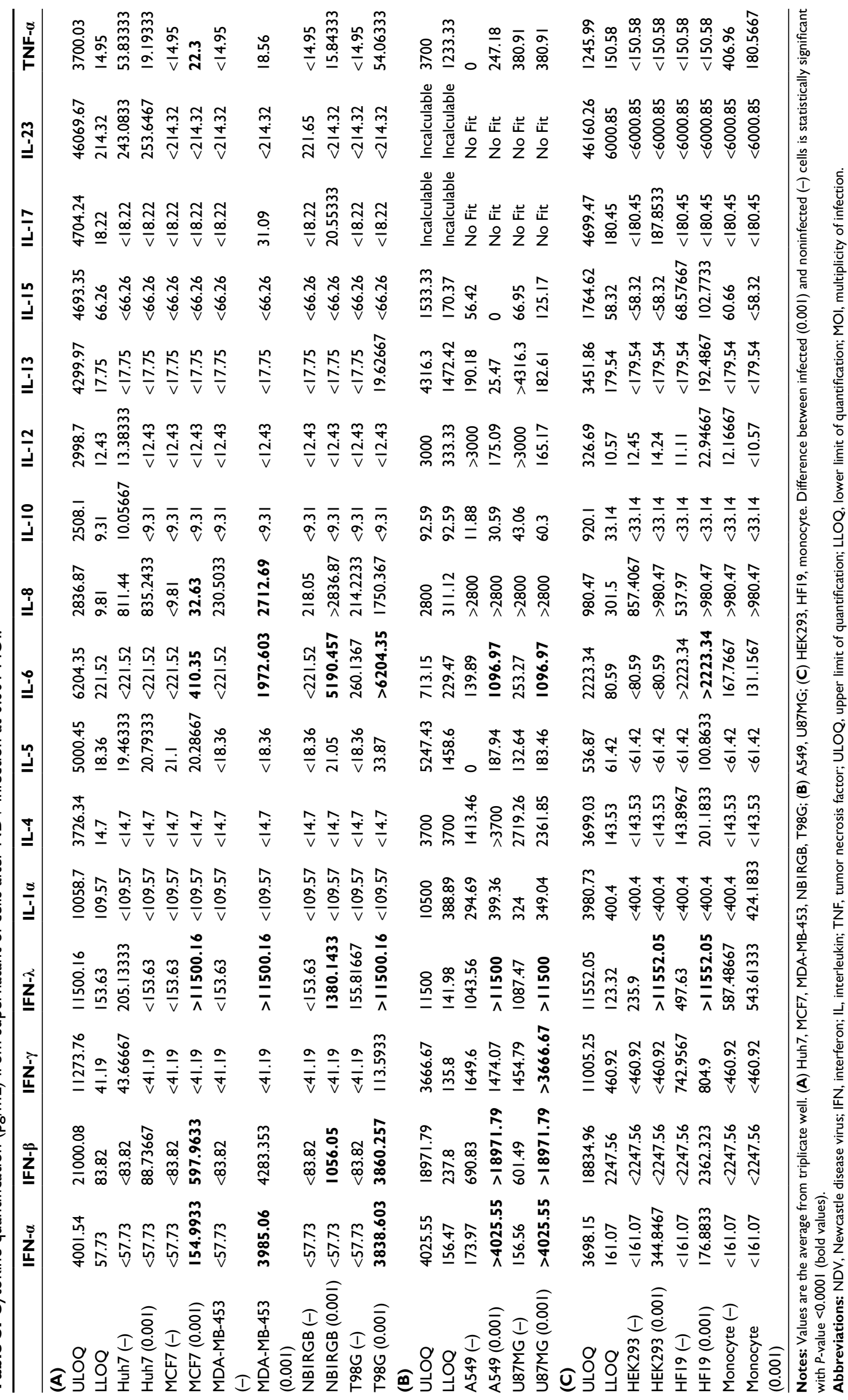




\section{Publish your work in this journal}

Oncolytic Virotherapy is an international, peer-reviewed, open access online journal publishing original research, study protocols, reviews, editorials and commentaries on all aspects of oncolytic virology, namely the application of oncolytic viruses for the treatment of cancer. Specific topics in the journal include: Rationale and theoretical aspects of oncolytic virotherapy including in vitro, in vivo and mathematical

Submit your manuscript here: http://www.dovepress.com/oncolytic-virotherapy-journal modeling; and practical application and problem solving in the clinic including identification of potential responders through biomarkers and genetic profiling. The manuscript management system is completely online and includes a very quick and fair peer-review system, which is all easy to use. Visit http://www.dovepress.com testimonials.php to read real quotes from published authors. 